\title{
The Chinese herbal formula Fuzheng Quxie Decoction attenuates cognitive impairment and protects cerebrovascular function in SAMP8 mice
}

This article was published in the following Dove Press journal:

Neuropsychiatric Disease and Treatment

\author{
Feixue Wang' \\ Jianchao Feng ${ }^{2}$ \\ Yang Yang' \\ Jiangang $\mathrm{Liu}^{3}$ \\ Meixia Liu' \\ Zhiyong Wang' \\ Hui Pei' \\ Yun Wei' \\ $\mathrm{Hao} \mathrm{Li}$ \\ 'Department of Geriatrics, Xiyuan \\ Hospital of China Academy of Chinese \\ Medical Sciences, Beijing, China; \\ ${ }^{2}$ Intensive Care Unit, Heze Hospital of \\ Traditional Chinese Medicine, Heze, \\ Shandong, China; ${ }^{3}$ Department of \\ Cardiology, Xiyuan Hospital of China \\ Academy of Chinese Medical Sciences, \\ Beijing, China
}

Correspondence: Yun Wei; Hao Li Department of Geriatrics, Xiyuan Hospital of China Academy of Chinese Medical Sciences, I Xiyuan Caochang Road, Haidian District, Beijing I0009I, China

Tel +86 I0 62835631

Email weiyun_0913@163.com;

xyhplihao1965@126.com
Purpose: This study was designed to explore the underlying mechanism of action for a Fuzheng Quxie Decoction (FQD) in Alzheimer's disease (AD), to validate its neuroprotective effects, and to provide experimental support for its predicted mechanism of action.

Methods: An integrative approach to network pharmacology was performed to predict the mechanism of action for treatment of AD with FQD. The predicted mechanism was validated in SAMP8 mice.

Results: With predicted putative FQD targets and a collection of AD-related genes, 245 possible regulatory targets of FQD were identified for the treatment of AD. Pathway-enrichment analysis for the possible regulatory targets indicated that vascular endothelial growth factor (VEGF) and VEGFreceptor signaling were pivotal in the treatment of $\mathrm{AD}$ with FQD. In vivo experiments confirmed the neuroprotective effect and the predicted mechanism of action for treatment of AD with FQD. Conclusion: This study contributes to an understanding of the neuroprotective effect of FQD and its potential mechanism of action for the treatment of AD.

Keywords: Alzheimer's disease, Fuzheng Quxie Decoction, network pharmacology, microcerebrovascular, vascular endothelial growth factor, hypoxia-induced factor $1 \alpha$

\section{Introduction}

Alzheimer's disease (AD) is a progressive neurodegenerative disease in aging populations that manifests as short- and long-term memory loss, learning and memory retention deficits, cognitive impairment, and behavioral and mental disability. ${ }^{1}$ By the year 2030, the number of AD patients is projected to reach 70 million, ${ }^{2}$ which represents a huge burden to society and the economy.

Current commonly used drugs for treatment of AD, eg, donepezil and memantine, target the cholinergic system and $N$-methyl-D-aspartate receptors. They can only relieve symptoms temporarily, rather than halt or slow disease progression. ${ }^{3}$ The pathogenesis of $\mathrm{AD}$ is intricate and not clear. Although senile plaques and neurofibrillary tangles, mainly composed of $\beta$-amyloid (A $\beta$ ) and tau, respectively, ${ }^{4,5}$ have been found to be the primary pathological features in the brains of AD patients, the development of different drugs targeting $A \beta$ or tau has been unsuccessful. ${ }^{6-11}$ Other proposed hypotheses for $\mathrm{AD}$ pathogenesis, such as oxidative stress and metal-ion accumulation, have been demonstrated to play a key role in blood-brain barrier (BBB) disruption, with $\mathrm{BBB}$ disruption possibly upstream of $\mathrm{A} \beta$ deposition and/or tau hyperphosphorylation in the pathogenic cascade that results in $\mathrm{AD}$ onset. ${ }^{12,13}$ 
Based on traditional Chinese medicine (TCM) theory, $\mathrm{AD}$ is believed to be caused by qi deficiency, blood stasis, and toxins. Qi deficiency and blood stasis are very common in the elderly. This condition results in metabolic waste that cannot be timely removed and with stasis is transformed into toxins. Qi deficiency, blood stasis, and toxins can be respectively interpreted into modern concepts of aging symptoms, hyperlipemia, and $\mathrm{A} \beta$ and tau-protein deposition. Accumulating data have demonstrated that medicinal Chinese herbs or herbal formulas, such as Radix Ginseng, ${ }^{14,15}$ Rhizoma Ligustici Chuanxiong, Rhizoma Coptidis, ${ }^{16,17}$ Qifu Yin,${ }^{18}$ and Huannao Yicong Decoction, ${ }^{19-22}$ tonify qi, dissolve blood stasis, and remove toxins to delay onset and progression of $\mathrm{AD}$, and these have been widely used in clinics to treat $\mathrm{AD}$ in China.

The herbal formula Fuzheng Quxie Decoction (FQD) was prescribed to patients with $\mathrm{AD}$ or cognitive impairment in accordance with TCM theory by the leader of this study Hao Li. FQD has been shown to alleviate AD symptoms and slow disease progression. ${ }^{16}$ The constitutive herbs of FQD are Radix Ginseng, Rhizoma Ligustici Chuanxiong, and Rhizoma Coptidis and are used in different TCM areas. FQD has been used widely in clinics to treat $\mathrm{AD}$ in China. Compared with other herbal formulas for $\mathrm{AD}$ treatment, FQD has the advantages of simple composition by virtue of optimized compatibility of herbs, economy, and convenience of preparation, with patient compliance comparatively high. Since a Chinese herbal formula consists of multiple compounds targeting different molecules, it is difficult to elucidate the underlying mechanistic basis for therapeutic disease treatment. However, it has become possible to interpret a Chinese herbal formula with the development of technologies and methodologies, such as network pharmacological approach which possesses the characteristics of holism similar to TCM. By means of network pharmacology, active compounds in a Chinese herbal formula can be identified and their potential targets defined. As such, the identification of the mechanistic basis for disease treatment using the Gene Ontology (GO) database and pathway-enrichment analysis is possible in the foreseeable future. ${ }^{23}$

Our previous study indicated that FQD was able to reduce tau hyperphosphorylation, ${ }^{24}$ but the underlying mechanistic basis was not determined. Therefore, in this study, active components of FQD were screened and possible targets and regulatory pathways predicted by network pharmacology. FQDpredicted mechanistic basis of action was validated in vivo, with results showing that $\mathrm{FQD}$ has a neuroprotective role in the treatment of $\mathrm{AD}$ by regulating predicted signaling pathways.

\section{Methods}

\section{Prediction of FQD mechanism of action for AD treatment}

\section{Active-compound screening}

The ingredients in three herbs contained in FQD were retrieved from the Traditional Chinese Medicine Systems Pharmacology Database and Analysis Platform (TCMSP; http://1sp.nwu.edu.cn/tcmsp.php), ${ }^{25}$ the TCM Database@ Taiwan (http://tcm.cmu.edu.tw) ${ }^{26}$ the Chinese Academy of Sciences Chemistry Database (http://www.organchem.csdb. $\underline{\mathrm{cn} / \mathrm{scdb} / \mathrm{default} . \mathrm{asp})}$, and the Traditional Chinese Medicines Integrated Database (TCMID). ${ }^{27}$ All the ingredients were combined to construct an FQD-ingredient database after removal of duplications. Since glycosides can be deglycosylated after oral administration, ${ }^{28}$ their deglycosylated forms were included in the database.

Active FQD compounds were screened by absorption, distribution, metabolism, and excretion (ADME) parameters, including oral bioavailability (OB), drug likeness (DL), and $\mathrm{BBB}$ permeability (BBBp). OB represents the percentage of an orally administered drug that distributes via systemic circulation..$^{29} \mathrm{DL}$ is an index of the structural similarities between an unknown compound and the compounds with the known structures in the Drug Bank database. Both OB and DL are key parameters for drug discovery. BBBp is the ability of a compound to penetrate the BBB. Compounds with BBBp $<-0.3$ do not penetrate the BBB, those with BBBp -0.3 to 0.3 have moderate penetration, and those with BBBp $>0.3$ have strong penetration. ${ }^{30}$ The BBBp of compounds in FQD was assessed because access to the brain is traditionally essential for treatment of AD. In this study, OB, DL, and BBBp were evaluated with the TCMSP calculation system. Active compounds were identified that had thresholds of $\mathrm{OB} \geq 30 \%, \mathrm{DL} \geq 0.18$, and $\mathrm{BBBp} \geq-0.3$, as described by Liu et al. ${ }^{30}$ Neuroprotective compounds that had been previously reported to exert an effect on the central nervous system were also considered active compounds, even if they did not meet the aforementioned criteria.

\section{Target prediction}

After active compounds had been identified, their targets were subsequently predicted by the online target-prediction systems TCMSP, TCMID, SwissTargetPrediction (http:// www.swisstargetprediction.ch), ${ }^{31}$ and STITCH (http:// stitch.embl.de). ${ }^{32}$ Each of these is mature and reliable, with integrated and optimized algorithms. Possible targets were calculated and predicted by uploading the structure of the compounds. Targets with prediction scores $>0.7$ 
were considered putative targets. The names of the targets were converted into gene symbols via UniProt (https://www. uniprot.org) $)^{33}$ to smooth subsequent network construction and analysis.

\section{Collection of AD-related genes}

There are several online databases of disease-related genes based on the published literature. In this study, AD-related genes were collected from Online Mendelian Inheritance in Man (https://omim.org), ${ }^{34}$ MalaCards (http://www.malacards. org), ${ }^{35}$ and the Kyoto Encyclopedia of Genes and Genomes (KEGG, http://www.genome.jp/kegg). ${ }^{36}$ After redundancy removal, all genes retrieved were combined into a database of AD-related genes.

\section{Construction of protein-protein interaction network}

Putative targets of FQD and AD-related genes were intersected to identify shared genes, which were defined as direct regulatory targets (DRTs) of FQD for the treatment of AD. A protein-protein interaction (PPI) network of DRTs was constructed with the BisoGenet 3.0 plug-in for Cytoscape 3.6. $0^{37}$ based on the online integrated PPI databases. ${ }^{38}$ In-house PPI databases, including the IntAct Molecular Interaction Database, Biological General Repository for Interaction Datasets, Database of Interacting Proteins, Human Protein Reference Database, Molecular Interaction Database, and Binding Database, were selected to predict interactions among proteins. The network was expressed with nodes and edges, which represented genes and their interactions, respectively. The PPI network was analyzed by one of its topological features - degree centrality (DC), ${ }^{39}$ which was calculated by the Centiscape 2.2.0 plug-in for Cytoscape. Genes represented by nodes with DC values greater than twice the average were considered to play a more important role in the network. These were chosen as possible regulatory targets (PRTs) of FQD for the treatment of AD.

\section{Enrichment analysis of PRTs}

In order to gain insight into the function of PRTs, their genes were annotated by GO enrichment analysis with FunRich $3.0,{ }^{40}$ which describes the functions of genes based on biological process, cellular component, and molecular function. ${ }^{41}$ The most significantly enriched terms of each category were visualized with OmicShare (http://www.omicshare.com). Further, to understand PRT-signaling pathways, pathwayenrichment analysis was performed and visualized with FunRich 3.0. Enriched signaling pathways were considered those that FQD primarily regulated in the treatment of AD. Predicted mechanisms were validated in vivo.

\section{Experimental validation}

Drugs and reagents for animal experimentation

The three medicinal herbs of FQD were purchased from Hebei Shennong (Beijing, China) Pharmaceutical. Extract preparation was carried out by the Department of Pharmaceutical Preparation at Xiyuan Hospital. Briefly, all herbs were combined and boiled for 30 minutes in distilled water, after which the liquid was collected. This was repeated and the liquids from each boiling mixed. An FQD extract was obtained by reduced-pressure distillation of the mixed liquid. There was $3.71 \mathrm{~g}$ of crude drug per gram of the extract. Components were detected by HPLC as described by Yang et al. ${ }^{24}$ Memantine was obtained from the National Institute for Food and Drug Control (batch number H20120268; Beijing, China), produced by Lundbeck (Copenhagen, Denmark). When used, the extract and memantine were dissolved separately in distilled water at intended concentrations.

Rabbit polyclonal anti-vascular endothelial growth factor (VEGF) antibody and rabbit polyclonal anti-hypoxia-induced factor $1 \alpha(\mathrm{HIF} 1 \alpha)$ antibody were provided by Abcam (Cambridge, UK). Mouse monoclonal anti- $\beta$-actin antibody was provided by ImmunoWay Biotechnology (Plano, TX, USA). Goat antirabbit/mouse IgG antibodies conjugated with HRP were provided by TDY Biotech (Beijing, China). The streptavidin-biotin complex kit, diaminobenzidine-substrate solution and enhanced chemiluminescence reagent were purchased from Thermo Fisher Scientific (Waltham, MA, USA). RIPA lysis buffer and a Micro BCA protein-assay kit were purchased from Sinoble Biotechnology Center (Beijing, China). Saline, paraformaldehyde, paraffin, H\&E kit, cresyl violet, PBS, BSA, and Tris-buffered saline Tween (TBST) were purchased from Beyotime Biotechnology (Haimen, China).

\section{Animal grouping and drug administration}

Animal experiments were carried out on male SAMP8 mice. SAMP8 mice spontaneously develop accelerated senescence, ${ }^{42}$ showing symptomatic characteristics typical of $\mathrm{AD}$, such as early memory and learning deficits, ${ }^{43,44}$ disturbed BBB function, accumulation of $\mathrm{A} \beta,{ }^{45}$ hyperphosphorylation of tau, ${ }^{46}$ and marked oxidant-stress pathology. ${ }^{47}$ These mice exhibit a similar pathological cascade to AD patients. Successful treatment of $\mathrm{AD}$ should improve memory, alleviate BBB dysfunction, and reduce oxidant stress in SAMP8 mice. ${ }^{48}$ In this study, FQD was predicted to regulate the VEGF pathway (see Results section), which is crucial for 
normal BBB function and prevention of the flux of $A \beta$ into the brain. For these reasons, SAMP8 mice were chosen as an appropriate model of AD.

A total of 40 male SAMP8 mice 3 months of age were housed in normal cages and kept in a controlled environment $\left(22^{\circ} \mathrm{C}, 50 \%\right.$ humidity, 12-hour light/dark cycle) with free access to water and food. After 1 week of adaptation, the mice were divided into four groups randomly: a memantine group, FQD high-dose group, FQD low-dose group, and a model group. Mice were treated orally once a day for 12 consecutive weeks with memantine at $2.6 \mathrm{mg} / \mathrm{kg}$ body weight, FQD at $2.6 \mathrm{~g}$ crude drug $/ \mathrm{kg}$ body weight, $\mathrm{FQD}$ at $1.3 \mathrm{~g}$ crude drug $/ \mathrm{kg}$ body weight, or distilled water of the same volume, respectively. Ten SAMR1 mice of the same age and genetic background as the SAMP8 mice served as a control group and were kept under the same conditions and given distilled water of the same volume. Two mice died when given the memantine gavage, and two mice died when given the high FQD dose due to operational mistakes. Animal experimentation was approved by the ethics committee of Xiyuan Hospital, China Academy of Chinese Medical Sciences (permit CACMS/20141220×21). All animal procedures were carried out in accordance with the Guide for the Care and Use of Laboratory Animals (8th edition) of the National Research Council.

\section{Morris water-maze test}

The Morris water maze (MWM) test was conducted after 12 weeks of treatment. ${ }^{49}$ The MWM apparatus, provided by Zhongshi Dichuang Technology (Beijing, China), consists of a circular water tank $120 \mathrm{~cm}$ in diameter and $50 \mathrm{~cm}$ deep, a platform $10 \mathrm{~cm}$ in diameter and $20 \mathrm{~cm}$ in height, and a computerized autoanalyzing camera system above the tank. The tank was divided into four quadrants, and the platform was placed at the very center of the fourth quadrant and $1 \mathrm{~cm}$ underwater. The water temperature was kept at $21^{\circ} \mathrm{C} \pm 1^{\circ} \mathrm{C}$. Four signs of different shapes (square, triangle, circle, and rhombus) were placed on the inner wall of each quadrant. Ink was used to stain the water black, ensuring that mice could not see the platform.

For the first 5 days, each mouse was placed into water at different entry points facing the tank wall (as shown in Figure 1) four times each day and allowed to search for the platform as training. The time required for each mouse to find the platform (latency to escape) was recorded automatically by the MWM software. If a mouse failed to reach the platform within 60 seconds, it was guided to the platform. All mice were allowed to stay on the platform for 10 seconds, after which they were dried and returned to their cages.

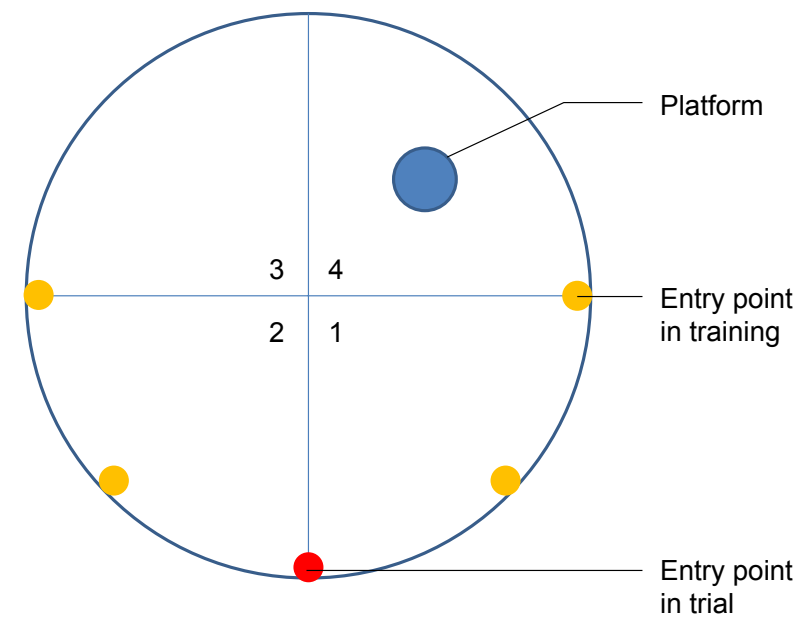

Figure I The position of platform and entry points in the MWM test. Abbreviation: MWM, Morris water maze.

On the sixth day, the platform was removed and spatialprobe trail analysis conducted. Each mouse was placed into water at a novel point facing the tank wall. During a 60 -second interval, mice were permitted to swim freely. The time and distance spent in the tank and in the fourth quadrant were recorded as indices.

\section{Passive-avoidance test}

On the third day after the MWM test had been completed, a passive-avoidance test was performed. The experimental apparatus, provided by Zhongshi Dichuang Technology, consists of a well-illuminated square compartment and a dark square compartment $\left(15 \times 15 \times 15 \mathrm{~cm}^{3}\right)$ with a removable roof and metal-grid floor for the administration of electric shocks. Between the two compartments there was a guillotine door. On the first day, each mouse was put into the illuminated compartment with free access to the dark compartment for 3 minutes to adapt to the environment. When the training began, the mice were given a weak electric shock to the foot $(0.5 \mathrm{~mA})$ as long as they were in the dark compartment. Then, the mice were returned to their cages. In order to test their memory, 24 hours later the same procedure was conducted without adaptation. The avoidance latency of mice entering the dark compartment for the first time was recorded and the number of times mice entered the dark compartment recorded as error times. If a mouse did not enter the dark compartment within the 5-minute test period, the test was terminated and avoidance latency recorded as 300 seconds. The training and test were conducted in an isolated experimental room with dim light.

\section{H\&E and Nissl staining}

After the behavioral study, all the mice were perfused transcardially with normal saline under deep anesthesia. Brains of the 
mice were removed after perfusion. Cortices were dissected from five of the left hemispheres and stored at $-80^{\circ} \mathrm{C}$ until used for Western blot (WB) analysis. The right hemispheres and another five of the left hemispheres were postfixed with $4 \%$ paraformaldehyde overnight. All dissections were completed on ice. The fixed hemispheres were paraffin-embedded and sliced into $20 \mu \mathrm{m}$-thick coronal sections, which were used for H\&E staining, Nissl staining and immunohistochemistry. Five sections from each group were stained with $H \& E$ to observe the morphology of the cerebral microvascular endothelial cells microscopically. Another five sections were stained with $0.75 \%$ cresyl violet for neuron analysis. Neurons in the hippocampus CA1 area were counted microscopically.

\section{Immunohistochemistry}

A series of sections containing the hippocampus and cortex from five of the left hemispheres of each group were deparaffinized, blocked with sheep serum, and reacted with anti-VEGF antibody and the biotinylated secondary antibody (anti-IgG antibody), with PBS washes between each step. Then, the prepared streptavidin-biotin complex solution was added, followed by diaminobenzidine-substrate solution. After tissue samples had been stained and mounted, three fields for each slide were assessed and the number of positive cells determined microscopically.

\section{Western blot analysis}

The prepared cortices dissected from the left hemispheres of each group were lysed in RIPA buffer and then centrifuged at $13,000 \mathrm{rpm}$ for 20 minutes at $4^{\circ} \mathrm{C}$ in a refrigerated centrifuge (Thermo Fisher Scientific). The supernatants were extracted and protein concentrations determined with the Micro BCA kit. The same amounts of protein were resolved and separated on $8 \%$ SDS-PAGE and transferred to polyvinylidene difluoride (PVDF) membranes (Thermo Fisher Scientific). After being blocked with $3 \%$ BSA-TBST for 30 minutes, PVDF membranes were incubated overnight at $4{ }^{\circ} \mathrm{C}$ with polyclonal rabbit anti-VEGF antibody and anti-HIF $1 \alpha$ antibody $(1: 1,000)$ in 3\% BSA-TBST. The PVDF membranes were washed with TBST and incubated for 40 minutes at room temperature with anti-IgG antibody conjugated with $\operatorname{HRP}(1: 10,000)$ dissolved in $1 \%$ BSA-TBST. Protein bands were detected with enhanced-chemiluminescence reagents and visualized with an imaging system (MicroChemi). Visualized protein bands were quantified with Image-Pro Plus 5.0 software.

\section{Statistical analysis}

All data are expressed as mean \pm SEM and were analyzed using GraphPad Prism 5.0 (GraphPad software, San Diego,
CA, USA). One-way ANOVA was used for intergroup comparisons. Least significant difference and Dunnett's $C$ test were used to assess the heterogeneity of variance. Differences were considered significant when $P<0.05$.

\section{Results}

\section{Mechanism prediction by network pharmacology FQD-ingredient and active-compound database}

The ingredients of each herb contained in FQD were retrieved from online databases, including TCMSP, TCM Database@ Taiwan, Chemistry Database, and TCMID. There were 199, 189, and 33 ingredients for Radix Ginseng, Rhizoma Ligustici Chuanxiong, and Rhizoma Coptidis, respectively. After redundancies had been deleted, a total of 401 ingredients were used to construct the FQD-ingredient database (Table S1).

Active compounds were ingredients that were able to be absorbed into the bloodstream and exert some function by protein regulation during disease treatment. Active compounds were screened based on ADME parameters, with 21, 9, and 7 compounds identified for each herb, respectively. Further, compounds known to be effective in treating central nervous system disease were added. The final total of 36 active FQD compounds is shown in Table 1.

\section{Potential targets of FQD}

Target fishing is the crucial step in mechanism prediction. Each screened active compound was able to interact with specific proteins based on its structure, with the possibility of a protective effect for some pathological process. By uploading the structure of each active compound to the online prediction systems/websites, potential targets/proteins for all the active compounds were acquired with one exception. Predicted targets for each compound are shown in Table 1. Ultimately, 236 predicted targets (putative targets) were obtained after deletion of duplicates (shown in Table S2). Some of the putative targets are related to pathological processes of AD such as acetylcholinesterase, caspase 3, LDLR, brain-derived neurotrophic factor (BDNF), and iNOS. To interpret function, further analyses were performed.

\section{AD-related genes}

AD-related genes were retrieved from Online Mendelian Inheritance in Man, MalaCards, and KEGG to profile proteins that might be involved in the pathogenesis of AD. Of these, 127, 293, and 171 genes were obtained from the three databases, respectively. All these were merged to construct an AD-related gene database comprised of 456 genes in total (Table S3). 
Table I Active compounds in FQD

\begin{tabular}{|c|c|c|c|c|c|}
\hline & OB (\%) & DL & BBBp & Source & Target number \\
\hline$R$-canadine & 55.36687 & 0.77465 & 0.57189 & Screened & 56 \\
\hline Alexandrine_qt ${ }^{\mathrm{a}}$ & 36.913906 & 0.75268 & 0.87952 & Screened & 28 \\
\hline Aposcopolamine & 66.646907 & 0.21999 & 0.40163 & Screened & 8 \\
\hline Arachidonate & 45.57325 & 0.20491 & 0.57974 & Screened & 56 \\
\hline Berberine & 36.86125 & 0.77665 & 0.56718 & Screened & 52 \\
\hline Berberrubine & $35.7355 I$ & 0.7269 & 0.17408 & Screened & 40 \\
\hline Berlambine & 36.6809 & 0.81596 & 0.17347 & Screened & 47 \\
\hline$\beta$-sitosterol & 36.913906 & 0.75123 & 0.98588 & Screened & 72 \\
\hline Celabenzine & 101.8826 & 0.48772 & 0.05084 & Screened & 11 \\
\hline Deoxyharringtonine & 39.27444 & 0.8116 & -0.24531 & Screened & 2 \\
\hline Diop & 43.593325 & 0.39247 & 0.26014 & Screened & 8 \\
\hline Epiberberine & 43.09233 & $0.776 \mathrm{I}$ & 0.39823 & Screened & 35 \\
\hline Ferulic acid & 39.56 & 0.06 & -0.03 & Literature $^{77-79}$ & 56 \\
\hline Frutinone A & 65.903731 & 0.34184 & 0.4604 & Screened & 27 \\
\hline Fumarine & 59.262505 & 0.82694 & -0.13192 & Screened & 46 \\
\hline Ginsenoside RbI & 6.24 & 0.04 & -5.6 & Literature $^{80-84}$ & 7 \\
\hline Ginsenoside Re & 4.27 & 0.12 & -4.39 & Literature $^{85-87}$ & 4 \\
\hline Ginsenoside RgI & 10.04 & 0.28 & -3.5 & Literature $^{88-90}$ & 5 \\
\hline Ginsenoside Rg5_qt & $39.56307 \mid$ & 0.78506 & 0.21243 & Screened & 0 \\
\hline Ginsenoside Rh4_qt & 31.112148 & 0.77829 & -0.18125 & Screened & 5 \\
\hline Girinimbine & 61.215303 & 0.31484 & 1.22221 & Screened & 23 \\
\hline Gomisin B & 31.990424 & 0.82858 & 0.17993 & Screened & 15 \\
\hline Inermin & 65.830931 & 0.53754 & 0.36121 & Screened & 35 \\
\hline Ligustilide & 23.5 & 0.07 & 1.2 & Literature $^{91-93}$ & 6 \\
\hline Ligustrazine & 20.01 & 0.03 & 1.05 & Literature ${ }^{94-96}$ & 6 \\
\hline Magnograndiolide & 63.70888 & 0.18833 & -0.24386 & Screened & 7 \\
\hline Malkangunin & 57.713844 & 0.62642 & -0.17138 & Screened & 5 \\
\hline Mandenol & 41.9962 & 0.19321 & 1.13821 & Screened & 8 \\
\hline Myricanone & 40.597566 & 0.51262 & -0.07932 & Screened & 25 \\
\hline Palmatine & 64.60111 & 0.64524 & 0.37072 & Screened & 45 \\
\hline Panaxadiol & 33.087961 & 0.79404 & $0.2266 \mathrm{I}$ & Screened & 3 \\
\hline Perlolyrine & 65.947753 & 0.2747 & 0.1464 & Screened & 12 \\
\hline Senkyunone & 47.663947 & 0.24435 & 0.5013 & Screened & 6 \\
\hline Stigmasterol & 43.829852 & 0.75665 & 1.00045 & Screened & 61 \\
\hline Suchilactone & 57.518824 & 0.55573 & 0.27669 & Screened & 32 \\
\hline Wallichilide & 42.310679 & 0.70639 & 0.73257 & Screened & 7 \\
\hline
\end{tabular}

Note: aCompounds with the suffix “_qt" refer to the deglycosylated form of their prototypes.

Abbreviations: BBBp, blood-brain barrier permeability; DL, drug likeness; FQD, Fuzheng Quxie Decoction; OB, oral bioavailability.

\section{Determination of DRTs and PRTs by PPI-network}

\section{construction and analysis}

After intersection of the putative FQD targets and AD-related genes, 31 DRTs were defined and considered the key proteins that FQD can regulate in AD (Figure 2 and Table 2). With 31 DRTs as seeds, a PPI network with 1,814 nodes and 34,063 edges was constructed. The BisoGenet plug-in was used to calculate the DC of each node in the network, with an average DC value for all nodes of 37 . There were 245 nodes with greater DC value than twice the average, and the genes represented by these nodes can be regarded as PRTs of FQD for treatment of AD (Figure 3 and Table S4).

GO and pathway-enrichment analysis for PRTs

GO enrichment analysis annotated all the PRTs for three aspects: biological process, cellular component, and molecular

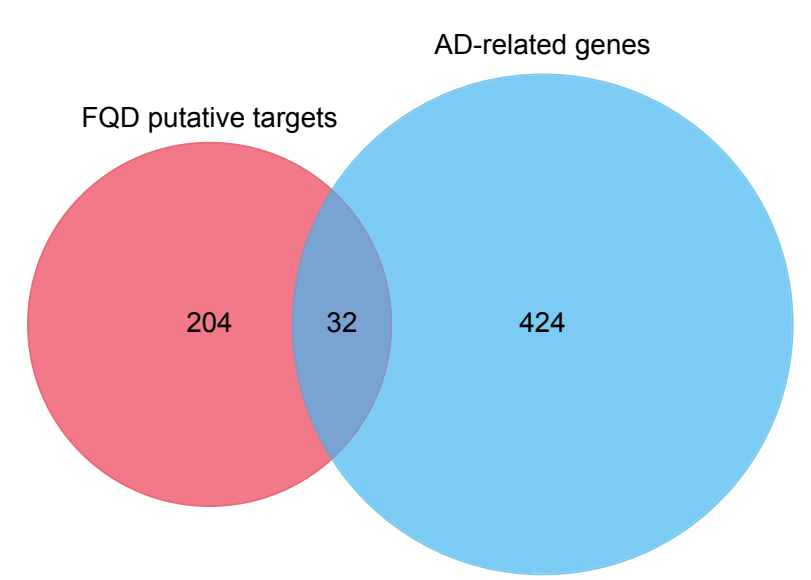

Figure 2 Intersections of putative FQD targets and AD-related genes; 32 shared genes were obtained, which were defined as DRTs.

Abbreviations: AD, Alzheimer's disease; DRTs, direct regulatory targets; FQD, Fuzheng Quxie Decoction. 
Table 2 Shared genes of putative FQD targets and AD-related genes (DRTs)

\begin{tabular}{|c|c|c|}
\hline Target/protein name & UniProt ID & Gene \\
\hline ATP-binding cassette subfamily A member I & ABCAI_HUMAN & $A B C A I$ \\
\hline Acetylcholinesterase & ACES_HUMAN & $A C H E$ \\
\hline Apolipoprotein E & APOE_HUMAN & APOE \\
\hline Cholinesterase & CHLE_HUMAN & $B C H E$ \\
\hline Brain-derived neurotrophic factor & BDNF_HUMAN & BDNF \\
\hline Voltage-dependent L-type calcium channel subunit $\alpha_{\text {IS }}$ & CACIS_HUMAN & CACNAIS \\
\hline Calmodulin I & CALM_HUMAN & CALMI \\
\hline Caspase 3 & CASP3_HUMAN & CASP3 \\
\hline C-C chemokine receptor type 2 & CCR2_HUMAN & CCR2 \\
\hline Choline $O$-acetyltransferase & CLAT_HUMAN & CHAT \\
\hline Neuronal acetylcholine receptor protein, $\alpha_{7}$ chain & ACHA7_HUMAN & CHRNA7 \\
\hline Cytochrome C, somatic & CYC_HUMAN & CYCS \\
\hline Cytochrome P450 2D6 & CP2D6_HUMAN & CYP2D6 \\
\hline 24-Dehydrocholesterol reductase & DHC24_HUMAN & DHCR24 \\
\hline Dual-specificity tyrosine-phosphorylation-regulated kinase IA & DYRIA_HUMAN & DYRKIA \\
\hline Glycogen synthase kinase $3 \beta$ & GSK3B_HUMAN & GSK3B \\
\hline Heme oxygenase I & HMOXI_HUMAN & HMOXI \\
\hline 5-Hydroxytryptamine $2 \mathrm{~A}$ receptor & 5HT2A_HUMAN & HTR2A \\
\hline Low-density-lipoprotein receptor & LDLR_HUMAN & $L D L R$ \\
\hline Low-density-lipoprotein receptor-related protein 8 & LRP8_HUMAN & LRP8 \\
\hline Amine oxidase (flavin-containing) A & AOFB_HUMAN & MAOB \\
\hline Microtubule-associated protein 2 & MTAP2_HUMAN & MAP2 \\
\hline Mitogen-activated protein kinase I & MKOI_HUMAN & MAPKI \\
\hline Mitogen-activated protein kinase 3 & MK03_HUMAN & MAPK3 \\
\hline Microtubule-associated protein tau & TAU_HUMAN & MAPT \\
\hline Nitric oxide synthase, inducible & NOS2_HUMAN & NOS2 \\
\hline Nitric oxide synthase, endothelial & NOS3_HUMAN & NOS3 \\
\hline Urokinase-type plasminogen activator & UROK_HUMAN & PLAU \\
\hline Prostaglandin G/H synthase 2 & PGH2_HUMAN & PTGS2 \\
\hline Sodium-dependent serotonin transporter & SC6A4_HUMAN & SLC6A4 \\
\hline Tumor necrosis factor & TNFA_HUMAN & TNF \\
\hline Very-low-density-lipoprotein receptor & VLDLR_HUMAN & $V L D L R$ \\
\hline
\end{tabular}

Abbreviations: FQD, Fuzheng Quxie Decoction; DRTs, direct regulatory targets.

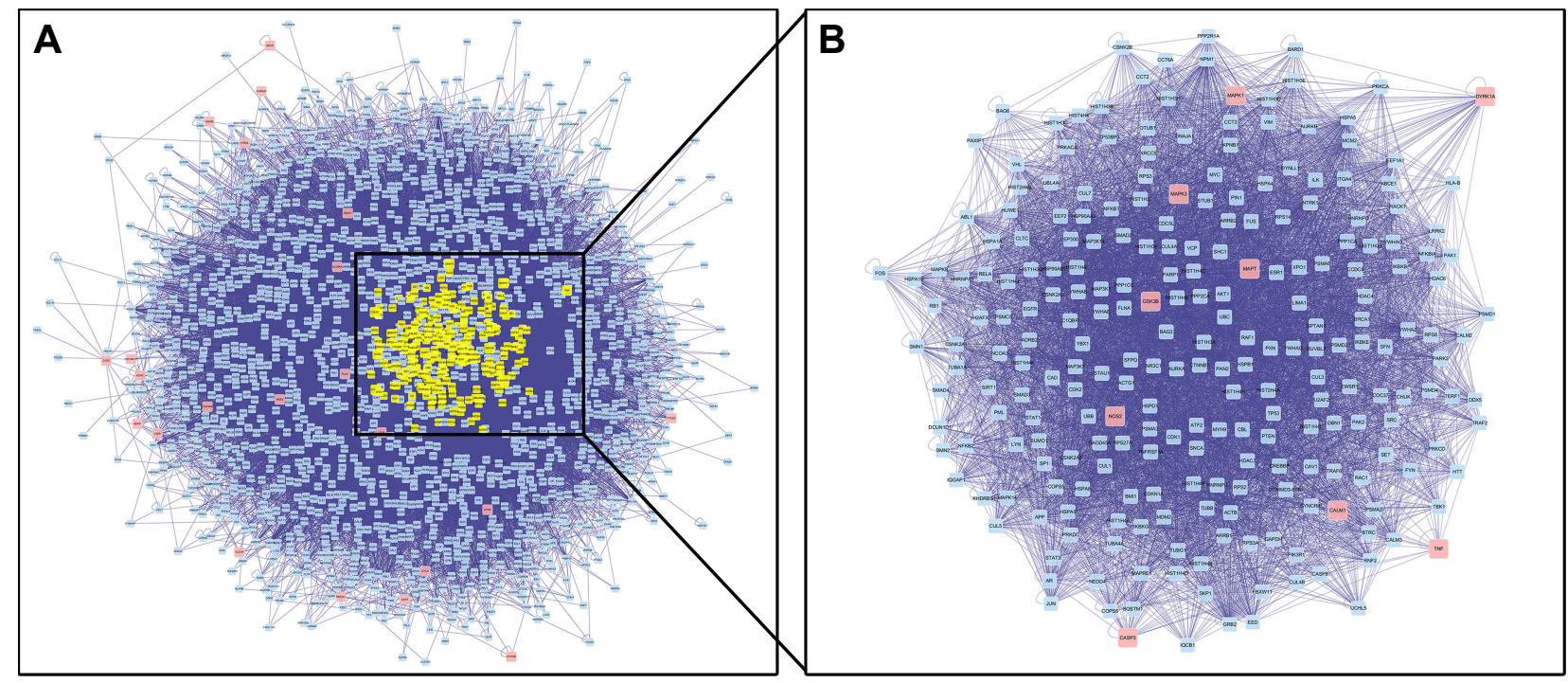

Figure 3 PPI network of DRTs and PRTs.

Notes: (A) PPI network with 32 DRTs as seeds. Pink nodes represent the 32 DRTs, blue nodes represent the proteins that have been reported to have interactions with the DRTs, and yellow nodes represent 245 PRTs with a DC value greater than twice the average. (B) PPI network of the 245 chosen PRTs, with nine DRTs (pink nodes). Abbreviations: DC, degree centrality; DRTs, direct regulatory targets; PPI, protein-protein interaction; PRTs, possible regulatory targets. 
function. The most significantly enriched terms for these three categories are shown in Figure 4. Most of the 245 PRTs were involved in cellular processes, metabolic processes, and signaling transduction, through binding of other proteins.

Pathway-enrichment analysis can assist in identification of major signaling pathways in which genes participate. Through pathway enrichment, 245 PRTs were enriched in the VEGF signaling network. Pathways of activator protein 1 (AP1) transcription factor, small mothers against decapentaplegic homolog 2/3 (SMAD2/3), transforming growth factor $\beta$ (TGF $\beta$ ), and integrin-linked kinase were also significantly enriched, as shown in Figure 5. VEGF promotes the proliferation and migration of the endothelium, playing a vital role in vascular permeability, especially the permeability of the BBB. Vascular impairment and BBB compromise have been widely acknowledged as important contributors to AD pathology. Regulating the expression of VEGF and involved pathways may ameliorate cerebrovascular function and thus protect neural function. Based on this network pharmacological analysis, it is hypothesized that FQD treatment of AD is by regulation of the VEGF-signaling pathway. As HIF $1 \alpha$ is a transcription factor that regulates the expression of VEGF, a role for HIF1 $\alpha$ was investigated.

\section{Animal experimentation}

Effect of FQD on spatial learning and memory ability In the MWM test, when compared to the control group, the ratio of time spent in the platform quadrant to total swimming (time ratio) decreased significantly in the model group, which was also observed for distance ratio $(P<0.01)$. When compared to the model group, both the time ratio and distance ratio increased in drug-administered groups, which was especially significant in the FQD high-dose group $(P<0.01$ and $P<0.05$, respectively; Figure 6).

\section{Effect of FQD on memory-retention ability}

In the passive-avoidance test, when compared to the control group, avoidance latency was shortened $(P<0.01)$, while error times decreased significantly $(P<0.05)$ in the model group. Compared with the model group, avoidance latency was shortened significantly in the memantine and FQD low-dose groups ( $P<0.01$ and $P<0.05$, respectively). For all drug-administration groups, error times decreased significantly $(P<0.05$; Figure 7$)$.

\section{Effect of FQD on cerebrovascular cortex}

H\&E staining showed that in the cortices of the control group, structures of the cerebrovascular endothelial cells (CECs) were clear, microvascular walls were smooth and intact, and surrounding spaces able to be observed, while in the cortices of the model group, the shape and arrangement of CECs and vascular walls were deformed, and surrounding spaces increased. Moreover, bleeding was observed due to broken vascular walls (or the BBB). The number of capillaries decreased. After administration of memantine and FQD,

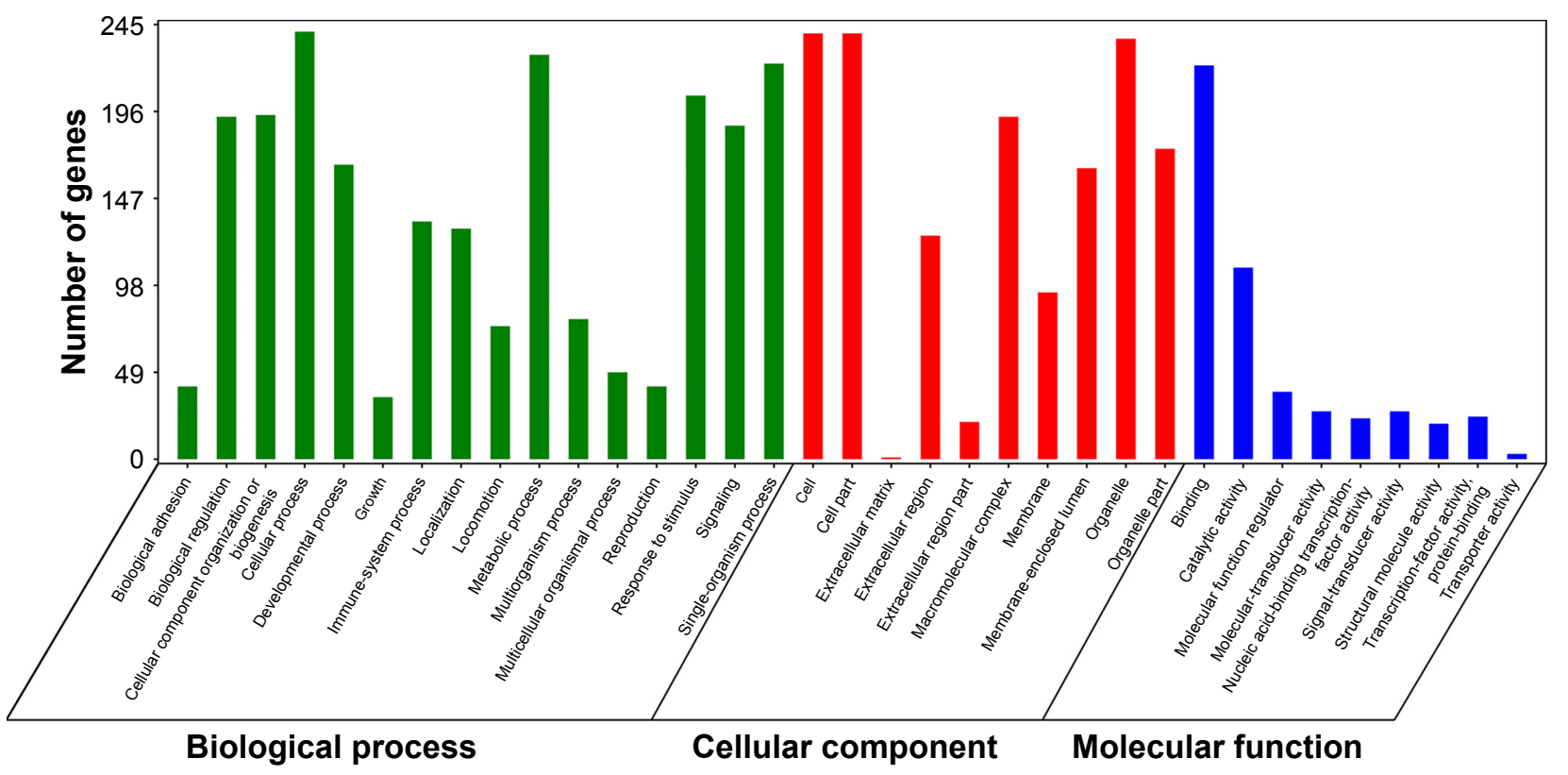

Figure 4 GO enrichment of 245 PRTs. Most significantly enriched terms are displayed. Abbreviations: GO, gene ontology; PRTs, possible regulatory targets. 


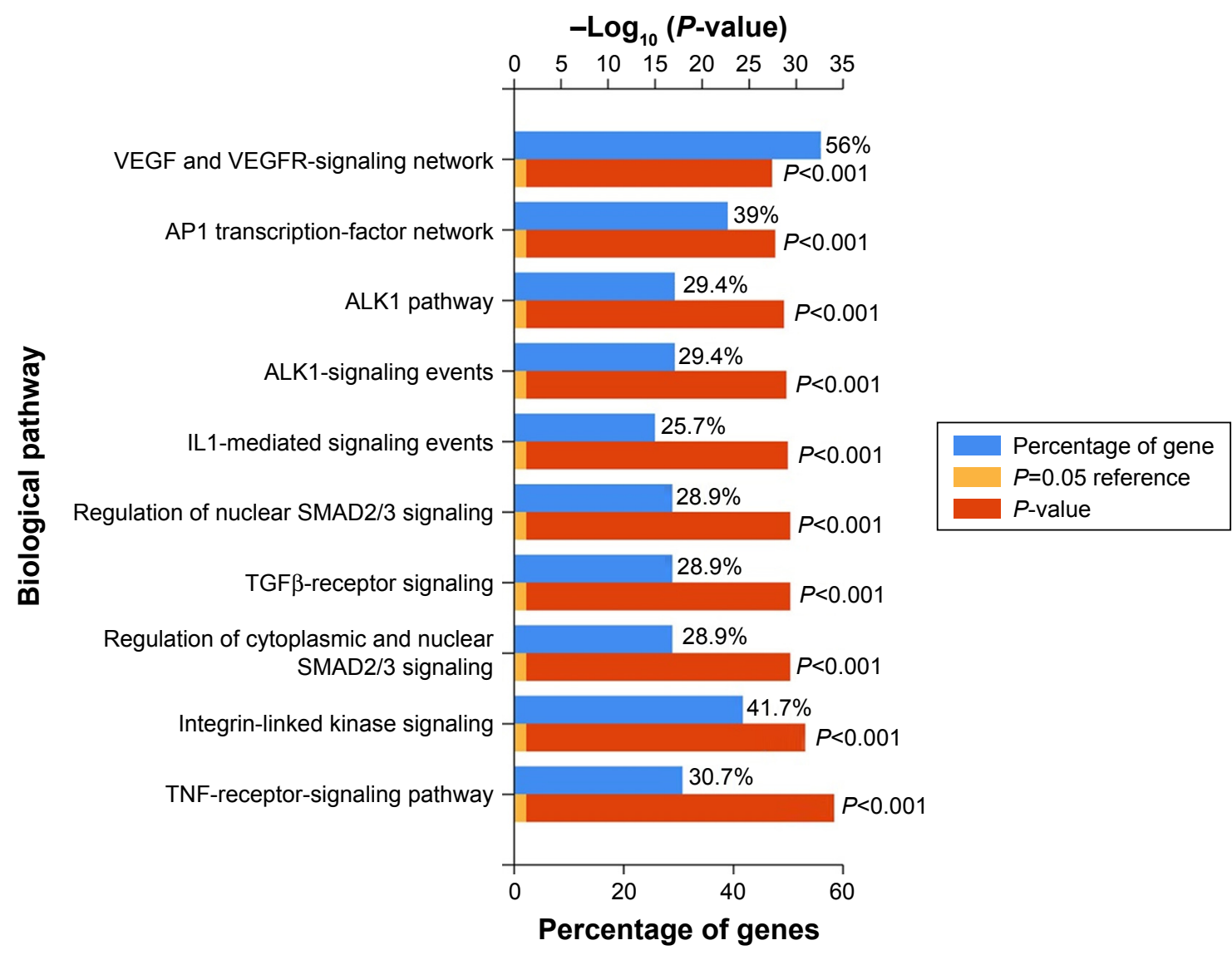

Figure 5 The top-ten enriched pathways of the 245 PRTs analyzed by FunRich 3.0.

Abbreviations: PRTs, possible regulatory targets; VEGF, vascular endothelial growth factor; VEGFR, VEGF-receptor.

there were significant improvements in the shape and arrangement of CECs, with vascular walls more intact and smooth, surrounding spaces decreased, and capillary numbers higher. The results are shown in Figure 8.

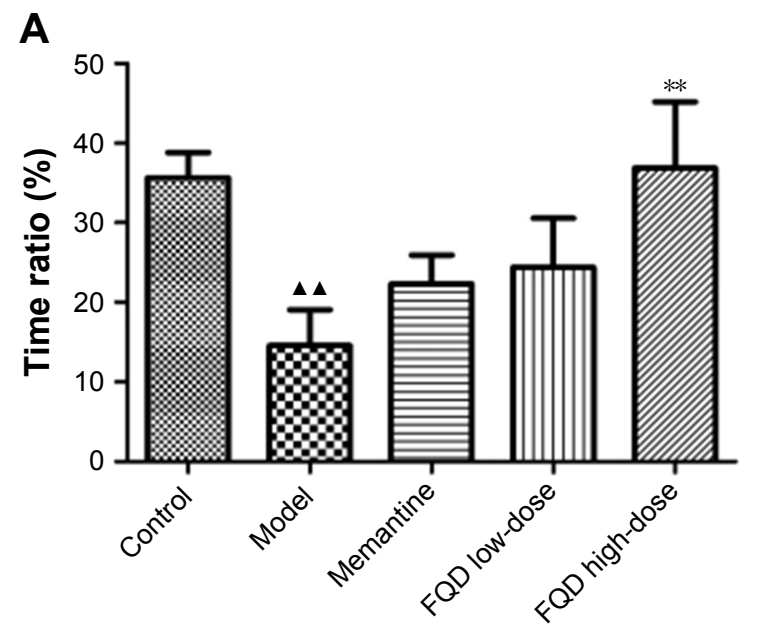

\section{Effect of FQD on neuronal morphology in} hippocampus

Nissl staining showed that neurons in the hippocampal CA1 region of the control group were neat, the cytoplasm

B

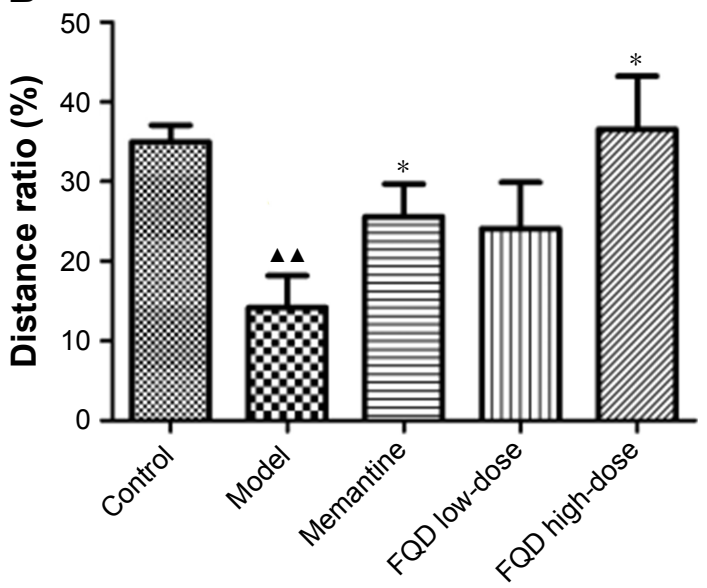

Figure 6 Effect of Fuzheng Quxie Decoction (FQD) on spatial learning and memory ability of SAMP8 mice.

Notes: (A) Ratio of time in platform quadrant to total swimming time; (B) ratio of swimming distance in platform quadrant to total swimming distance. ( ${ }^{\wedge} P<0.01$ vs control group; $* P<0.05, * * P<0.01$ vs model group; $n=10$ ). 
A

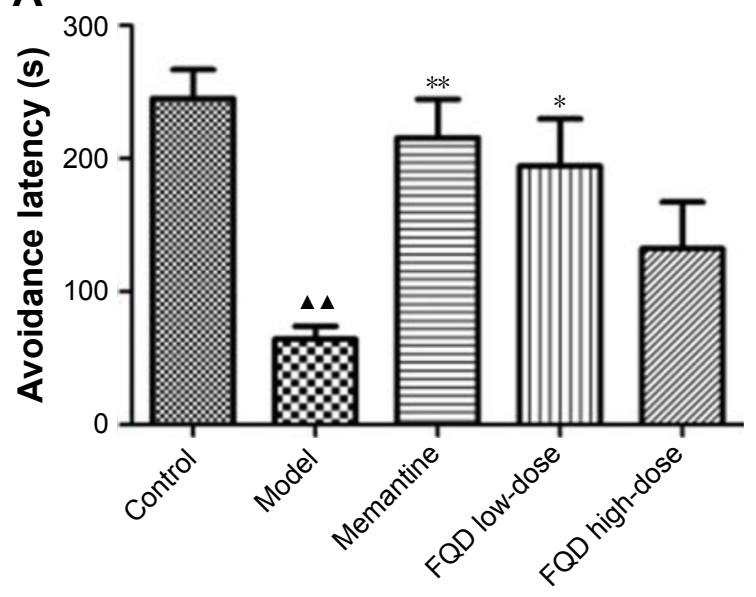

B

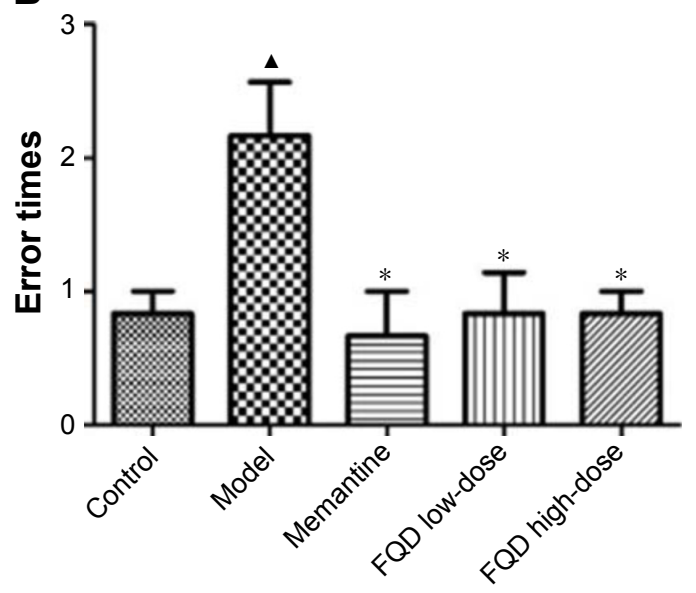

Figure 7 Effect of Fuzheng Quxie Decoction (FQD) on memory-retention ability of SAMP8 mice.

Notes: (A) Avoidance latency that mice spent to come into dark compartment for the first time; (B) error times in the dark compartment. ( ${ }^{\wedge} P<0.05,{ }^{\wedge} P<0.0$ I vs control group; $* \mathrm{p}<0.05, * * \mathrm{P}<0.01$ vs model group; $\mathrm{n}=10$ ).

dark blue, and nuclei light blue, with clear Nissl bodies within them. However, compared to the control group, neurons were disordered, the number of neurons significantly decreased, and the boundaries of the Nissl bodies were blurred, with some nuclei or Nissl bodies pyknotic or even dissolved. When compared to the model group, neurons were arranged better, numbers of neurons and Nissl bodies increased, and nuclear pyknosis partially alleviated after drug administration. The results are shown in Figure 9.

\section{Effect of FQD on VEGF expression}

With immunohistochemistry and WB, VEGF expression was assessed. On immunohistochemistry, the number of VEGFpositive cells decreased significantly $(P<0.01)$ in the model group when compared to the control group. Compared to the model group, the number of VEGF-positive cells increased significantly in the memantine and FQD high-dose group $(P<0.05$ and $P<0.01$, respectively). However, on $\mathrm{WB}$, there was no significant difference in VEGF expression in these groups. Results are shown in Figure 10.
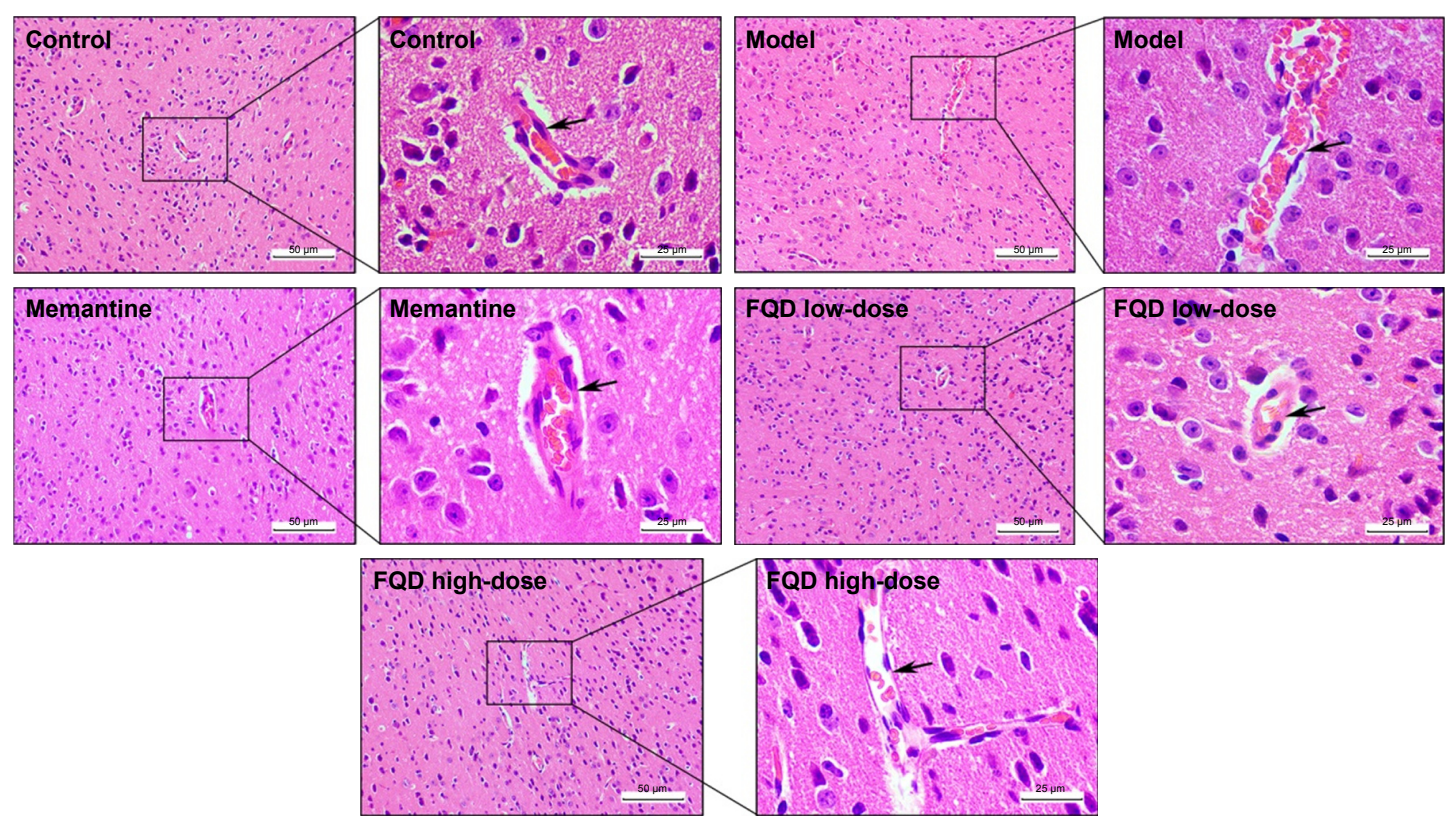

Figure 8 Effect of Fuzheng Quxie Decoction (FQD) on cerebrovascular morphology in the cortex of SAMP8 mice. Note: H\&E staining, magnification $100 \times$ and $400 \times$. 

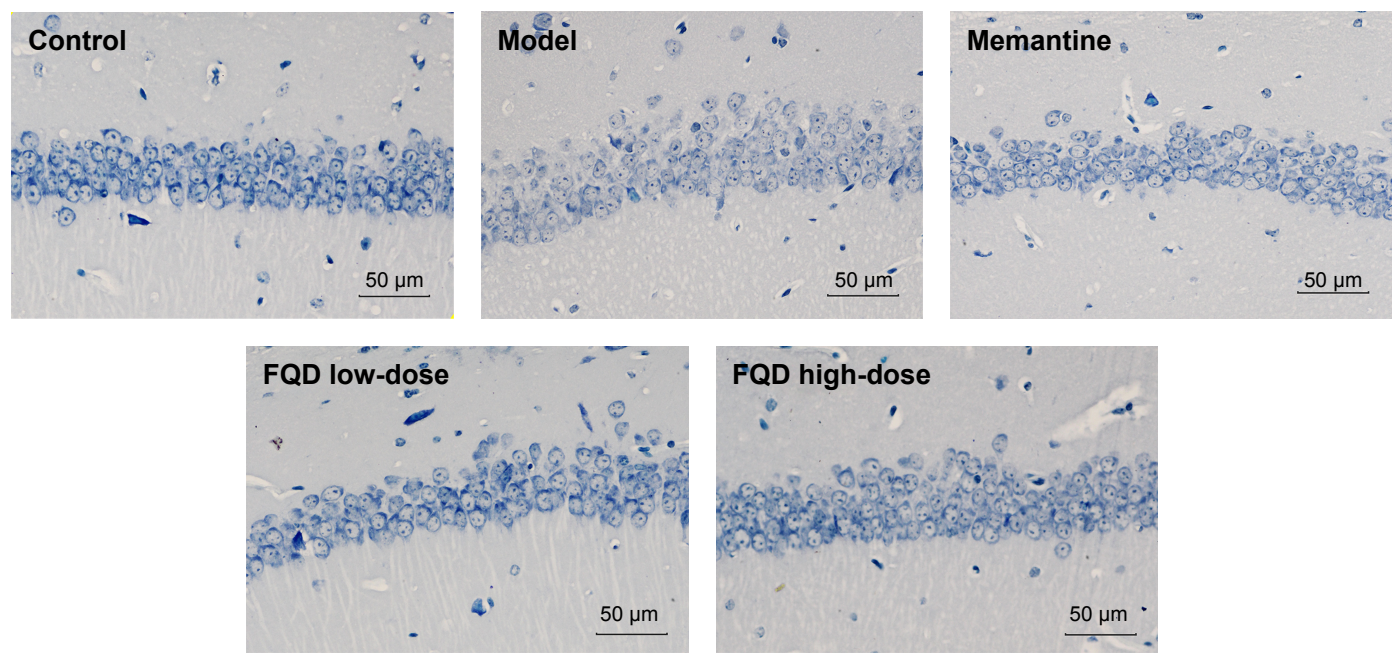

Figure 9 Effect of Fuzheng Quxie Decoction (FQD) on neuronal morphology in hippocampus CAI region of SAMP8 mice. Note: Nissl staining, magnification 200x.

\section{Effect of FQD on HIFI $\alpha$ expression}

On WB, HIF $1 \alpha$ expression in the model group increased significantly $(P<0.05)$ when compared to the control group. When compared to the model group, HIF1 $\alpha$ expression decreased in the memantine and FQD low-dose groups $(P<0.05)$, and the decrease was especially significant in FQD high-dose group $(P<0.01)$. The results are shown in Figure 11.
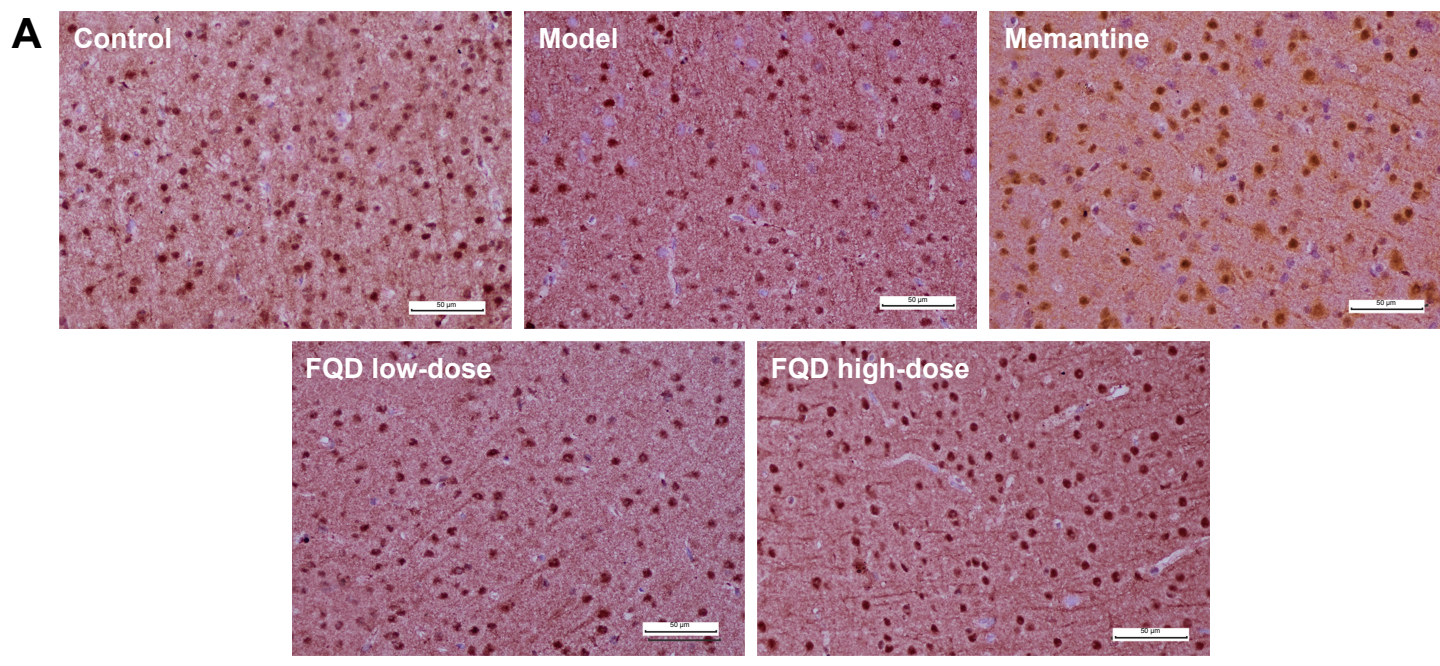

B

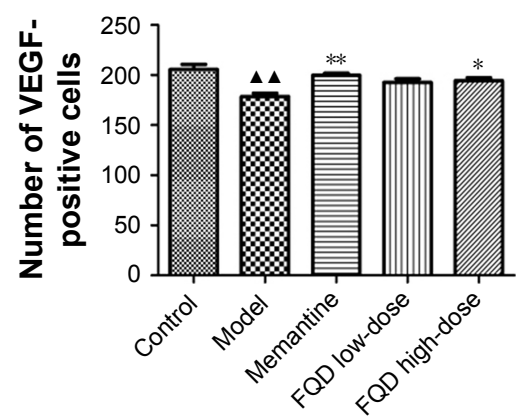

C

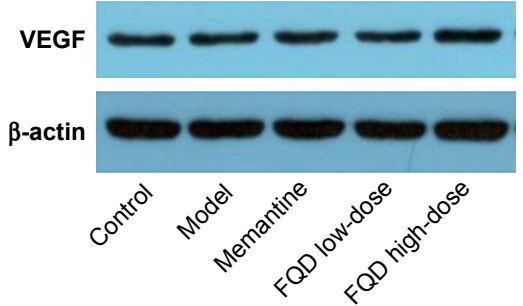

D

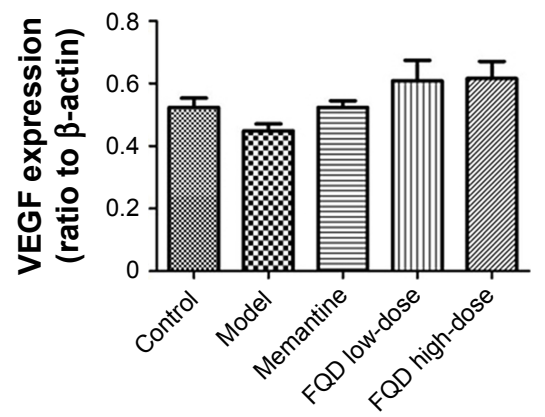

Figure 10 Effect of Fuzheng Quxie Decoction (FQD) on VEGF expression in brains of SAMP8 mice.

Notes: (A) VEGF-positive cells in cortex by immunohistochemistry (magnification 400x); (B) quantification of VEGF-positive cells in cortex; (C) VEGF bands detected by Western blot analysis; (D) quantification of VEGF expression, normalized as ratio to $\beta$-actin. ${ }^{\Delta}{ }^{\wedge}<0.0$ I vs control group; $* P<0.05$, ${ }^{* * P}<0.0$ I vs model group (B and $\mathbf{D}$ ). 

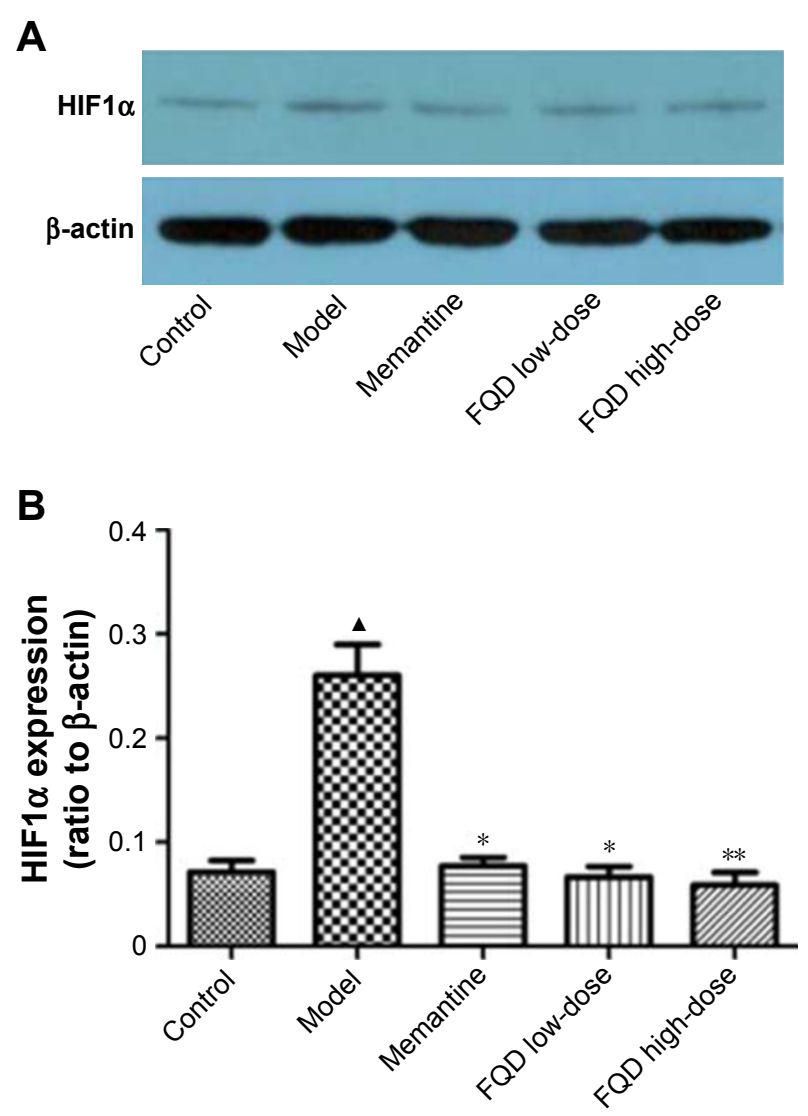

Figure I I Effect of Fuzheng Quxie Decoction (FQD) on hypoxia-induced factor I $\alpha$ $(\mathrm{HIFI} \alpha)$ expression in brains of SAMP8 mice.

Notes: (A) HIFI $\alpha$ bands detected by Western blot analysis; (B) shows the quantification of HIFI $\alpha$ expression normalized as the ratio to $\beta$-actin. $\left({ }^{\wedge} P<0.05\right.$ vs control group; $* \mathrm{P}<0.05, * * \mathrm{p}<0.0$ I vs model group; $\mathrm{n}=5$ ).

\section{Discussion}

Predictions for the mechanisms of action of Chinese herbal formulas in disease are often assessed through network pharmacological approaches..$^{50}$ Herein, the composition of FQD was collected and its predicted active compounds were assessed by ADME parameters. The targets of FQD were identified as acetylcholinesterase, apolipoprotein, low-density lipoprotein receptor (LDLR), caspase 3, brain-derived neurotrophic factor (BDNF), and inducible nitric oxide synthases (iNOS), which are involved in neural transmission, lipid metabolism, cellular apoptosis, and inflammation. Each of these is a key biomarker ${ }^{51}$ of AD pathogenesis. ${ }^{51-55}$ It is likely that $\mathrm{AD}$-symptom improvement could be accomplished by regulation of these biomarkers, which would demonstrate the reliability of this predictive network pharmacology. By GO and KEGG enrichment analysis, FQD was found primarily to regulate the VEGF pathway and may be a means by which to treat AD. Regulating the VEGF pathway has been proposed as an approach to enhance cerebral vasculature function and consequently alleviate $\mathrm{AD}$ symptoms. ${ }^{56,57}$

With increasing age, cerebral blood flow is gradually reduced, and this reduction has been proposed as the basic reason for $\mathrm{AD}$ onset. ${ }^{58,59}$ Reduced cerebral blood flow is attributed to vascular aging and reduced angiogenesis, in which VEGF plays a key role.$^{60} \mathrm{VEGF}$ interacts with VEGFreceptor in the cerebral endothelium and in neurons, not only acting as the main regulator of angiogenesis but also as a contributor to neurogenesis and neuroprotection. ${ }^{61} \mathrm{In}$ older people, angiogenesis is impaired by reduced numbers of endothelial progenitor cells and/or reduced expression of VEGF. ${ }^{62,63}$ VEGF expression in AD patients is reduced ${ }^{56}$ with treatments aimed at VEGF beneficial to neuronal survival. ${ }^{64-66}$ In this study, FQD treatment upregulated VEGF expression, which may facilitate angiogenesis and increase cerebral blood flow, as well as neurogenesis, with each beneficial to cognition. During hypoperfusion, HIF $1 \alpha$ is activated to promote VEGF expression, but if HIF $1 \alpha$ is overactivated, large amounts of VEGF will increase the permeability of the BBB. Herein, FQD downregulated HIF $1 \alpha$ expression, which would maintain HIF $1 \alpha$ and VEGF at stable levels.

Besides $\mathrm{A} \beta$ and tau hyperphosphorylation in $\mathrm{AD}$, cerebrovascular pathology has been proposed as an important contributor to the onset of $\mathrm{AD},{ }^{67}$ in that there is vascular luminal stenosis, decreased numbers of capillaries, thickened basement membranes, and increased BBB permeability. Several vascular risk factors contribute to $\mathrm{AD}$ pathology, such as hypertension, atherosclerosis, diabetes mellitus, smoking, and obesity, which attack the cerebral vasculature in the early stages of $\mathrm{AD} .{ }^{68-71}$ This study suggests that prevention or reversal of vascular pathological changes and development of drugs that improve cerebral vasculature may reduce the development of AD.

SAMP8 mice have been used widely to study AD. ${ }^{47,72}$ These mice have features of vascular pathology, ${ }^{73,74}$ which permitted an assessment of the effect of FQD on regulatory vascular pathways. The memory capacity of mice was assessed by the MWM and passive-avoidance tests, which assess long-term memory and short-term memory, respectively. ${ }^{75,76}$ Based on these results, FQD had a significant effect on short- and long-term memory in mice. Consistently with these findings, H\&E and Nissl staining showed vasculoprotective and neuroprotective effects for FQD. The potential mechanism may be by regulation of the VEGF pathway. Future studies confirming these findings should be carried out in future. 


\section{Conclusion}

Numerous compounds are found within each herb. As such, targets for Chinese herbal formulas are difficult to confirm. This study demonstrated the reliability and possibility of network pharmacology for interpretation of the mechanism of action for disease treatment by herbal formulae. Despite their reliability, the predicted results require subsequent validation in vivo. In this study, we not only demonstrated the neuroprotective effects of FQD but also validated the predicted mechanism of action underlying the effect of the herbal formula. As a preliminary study, only the regulatory effect of FQD on the expression of VEGF and HIF1 $\alpha$ was explored. The role of other proteins or mRNAs in the VEGF pathway and the regulatory effect of FQD on them should be studied further in AD.

\section{Acknowledgment}

This work was supported by the National Natural Science Foundation of China (grants 81503628 and 81573819).

\section{Author contributions}

FW and JF participated in manuscript preparation, network pharmacological analysis, and animal experimentation. YY, $\mathrm{JL}, \mathrm{ML}, \mathrm{ZW}$, and HP participated in animal experimentation, data analysis, and manuscript revision. YW and HL designed the study, supervised the study process, and edited the manuscript. All authors contributed toward data analysis, drafting and critically revising the paper, gave final approval of the version to be published, and agree to be accountable for all aspects of the work.

\section{Disclosure}

The authors report no conflicts of interest in this work.

\section{References}

1. Buckner RL. Memory and Executive Function in Aging and AD. Neuron. 2004;44(1):195-208.

2. Alzheimer's disease facts and figures. Alzheimers Dement. 2017;13(4): 325-373.

3. Savelieff MG, Nam G, Kang J, Lee HJ, Lee M, Lim MH. Development of Multifunctional Molecules as Potential Therapeutic Candidates for Alzheimer's Disease, Parkinson's Disease, and Amyotrophic Lateral Sclerosis in the Last Decade. Chem Rev. 2018 Epub Aug 10.

4. Makin S. The amyloid hypothesis on trial. Nature. 2018;559(7715): S4-S7.

5. Grundke-Iqbal I, Iqbal K, Tung YC, Quinlan M, Wisniewski HM, Binder LI. Abnormal phosphorylation of the microtubule-associated protein tau (tau) in Alzheimer cytoskeletal pathology. Proc Natl Acad Sci U S A. 1986;83(13):4913-4917.
6. Behl C. Amyloid in Alzheimer's Disease: Guilty Beyond Reasonable Doubt? Trends Pharmacol Sci. 2017;38(10):849-851.

7. Hawkes N. Merck ends trial of potential Alzheimer's drug verubecestat. BMJ. 2017;356:j845.

8. Holmes C, Boche D, Wilkinson D, et al. Long-term effects of A $\beta 42$ immunisation in Alzheimer's disease: follow-up of a randomised, placebo-controlled phase I trial. Lancet. 2008;372(9634):216-223.

9. Karran E, Hardy J. A critique of the drug discovery and phase 3 clinical programs targeting the amyloid hypothesis for Alzheimer disease. Ann Neurol. 2014;76(2):185-205.

10. Lovestone S, Boada M, Dubois B, et al. A phase II trial of tideglusib in Alzheimer's disease. J Alzheimers Dis. 2015;45(1):75-88.

11. Gauthier S, Feldman HH, Schneider LS, et al. Efficacy and safety of tau-aggregation inhibitor therapy in patients with mild or moderate Alzheimer's disease: a randomised, controlled, double-blind, parallelarm, phase 3 trial. Lancet. 2016;388(10062):2873-2884.

12. Markesbery WR, Carney JM. Oxidative Alterations in Alzheimer's Disease. Brain Pathol. 2010;9(1):133-146.

13. Zatta P, Drago D, Bolognin S, Sensi SL. Alzheimer's disease, metal ions and metal homeostatic therapy. Trends Pharmacol Sci. 2009; 30(7):346-355.

14. Patel S, Rauf A. Adaptogenic herb ginseng (Panax) as medical food: Status quo and future prospects. Biomed Pharmacother. 2017;85:120-127.

15. Wang Y, Yang G, Gong J, et al. Ginseng for Alzheimer's Disease: A Systematic Review and Meta-Analysis of Randomized Controlled Trials. Curr Top Med Chem. 2016;16(5):529-536.

16. Yang Y, Jia X, Feng J, et al. Fuzheng Quxie Decoction Ameliorates Learning and Memory Impairment in SAMP8 Mice by Decreasing Tau Hyperphosphorylation. Evid Based Complement Alternat Med. 2017;2017(20):5934254.

17. Huang M, Jiang X, Liang Y, Liu Q, Chen S, Guo Y. Berberine improves cognitive impairment by promoting autophagic clearance and inhibiting production of $\beta$-amyloid in APP/tau/PS1 mouse model of Alzheimer's disease. Exp Gerontol. 2017;91:25-33.

18. Wang SY, Liu JP, Ji WW, et al. Qifu-Yin attenuates AGEs-induced Alzheimer-like pathophysiological changes through the RAGE/NF- $\kappa \mathrm{B}$ pathway. Chin J Nat Med. 2014;12(12):920-928.

19. Liu M, Wei Y, Yang Y, et al. Effects and Mechanism of Huannao Yicong Decoction Extract on the Ethology of Transgenic APP/PS1 Mice. Evid Based Complement Alternat Med. 2017;2017(2):9502067.

20. Wang ZY, Liu JG, Wei Y, et al. Huannao Yicong Formula () regulates $\gamma$-secretase activity through APH-1 and PEN-2 gene ragulation pathways in hippocampus of APP/PS1 double transgenic mice. Chin J Integr Med. 2017;23(4):270-278.

21. Yang Y, Liu JP, Fang JY, et al. Effect and Safety of Huannao Yicong Formula () on Patients with Mild-to-Moderate Alzheimer's Disease: A Randomized, Double-Blinded, Donepezil-Controlled Trial. Chin J Integr Med. Epub 2018 Aug 14.

22. Wang Q, Li H, Wang FX, et al. Huannao Yicong Decoction () extract reduces inflammation and cell apoptosis in $\mathrm{A} \beta_{1-42}$-induced Alzheimer's disease model of rats. Chin J Integr Med. 2017;23(9):672-680.

23. Li S, Zhang B. Traditional Chinese medicine network pharmacology: theory, methodology and application. Chin J Nat Med. 2013;11(2): $110-120$.

24. Yang YA-O, Xa-O J, Feng JA-O, et al. Fuzheng Quxie Decoction Ameliorates Learning and Memory Impairment in SAMP8 Mice by Decreasing Tau Hyperphosphorylation. Evid Based Complement Alternat Med. 2017;2017:5934254.

25. Ru J, Li P, Wang J, et al. TCMSP: a database of systems pharmacology for drug discovery from herbal medicines. J Cheminform. 2014; 6(1):13.

26. Chen CY. TCM Database@Taiwan: the world's largest traditional Chinese medicine database for drug screening in silico. PLoS One. 2011;6(1):e15939. 
27. Xue R, Fang Z, Zhang M, Yi Z, Wen C, Shi T. TCMID: Traditional Chinese Medicine integrative database for herb molecular mechanism analysis. Nucleic Acids Res. 2013;41(Database issue):D1089-D1095.

28. Németh K, Plumb GW, Berrin JG, et al. Deglycosylation by small intestinal epithelial cell beta-glucosidases is a critical step in the absorption and metabolism of dietary flavonoid glycosides in humans. Eur J Nutr. 2003;42(1):29-42.

29. Xu X, Zhang W, Huang C, et al. A novel chemometric method for the prediction of human oral bioavailability. Int J Mol Sci. 2012;13(6): 6964-6982.

30. Liu H, Wang J, Zhou W, Wang Y, Yang L. Systems approaches and polypharmacology for drug discovery from herbal medicines: an example using licorice. J Ethnopharmacol. 2013;146(3):773-793.

31. Gfeller D, Grosdidier A, Wirth M, Daina A, Michielin O, Zoete V. SwissTargetPrediction: a web server for target prediction of bioactive small molecules. Nucleic Acids Res. 2014;42(Web Server issue): W32-W38.

32. Szklarczyk D, Santos A, von Mering C, Jensen LJ, Bork P, Kuhn M. STITCH 5: augmenting protein-chemical interaction networks with tissue and affinity data. Nucleic Acids Res. 2016;44(D1):D380-D384.

33. Apweiler R, Bairoch $\mathrm{A}, \mathrm{Wu} \mathrm{CH}$, et al. UniProt: the Universal Protein knowledgebase. Nucleic Acids Res. 2004;32(Database issue): D115-D119.

34. Hamosh A, Scott AF, Amberger JS, Bocchini CA, Mckusick VA. Online Mendelian Inheritance in Man (OMIM), a knowledgebase of human genes and genetic disorders. Nucleic Acids Res. 2004;33(Database issue):D514-D517.

35. Rappaport N, Twik M, Plaschkes I, et al. MalaCards: an amalgamated human disease compendium with diverse clinical and genetic annotation and structured search. Nucleic Acids Res. 2017;45(D1):D877-D887.

36. Altermann E, Klaenhammer TR. PathwayVoyager: pathway mapping using the Kyoto Encyclopedia of Genes and Genomes (KEGG) database. BMC Genomics. 2005;6(1):60.

37. Shannon P, Markiel A, Ozier O, et al. Cytoscape: a software environment for integrated models of biomolecular interaction networks. Genome Res. 2003;13(11):2498-2504.

38. Martin A, Ochagavia ME, Rabasa LC, Miranda J, Fernandez-deCossio J, Bringas R. BisoGenet: a new tool for gene network building, visualization and analysis. BMC Bioinformatics. 2010;11(1):91.

39. Scardoni G, Petterlini M, Laudanna C. Analyzing biological network parameters with CentiScaPe. Bioinformatics. 2009;25(21): 2857-2859.

40. Pathan M, Keerthikumar S, Ang CS, et al. FunRich: An open access standalone functional enrichment and interaction network analysis tool. Proteomics. 2015;15(15):2597-2601.

41. Harris MA, Clark J, Ireland A, et al. The Gene Ontology (GO) database and informatics resource. Nucleic Acids Res. 2004;32(Database issue):D258-D261.

42. Takeda T, Hosokawa M, Takeshita S, et al. A new murine model of accelerated senescence. Mech Ageing Dev. 1981;17(2):183-194.

43. Yagi H, Katoh S, Akiguchi I, Takeda T. Age-related deterioration of ability of acquisition in memory and learning in senescence accelerated mouse: SAM-P/8 as an animal model of disturbances in recent memory. Brain Res. 1988;474(1):86-93.

44. Miyamoto M. Characteristics of age-related behavioral changes in senescence-accelerated mouse SAMP8 and SAMP10. Exp Gerontol. 1997;32(1-2):139-148.

45. Takemura M, Nakamura S, Akiguchi I, et al. Beta/A4 proteinlike immunoreactive granular structures in the brain of senescence-accelerated mouse. Am J Pathol. 1993;142(6):1887-1897.

46. Canudas AM, Gutierrez-Cuesta J, Rodríguez MI, et al. Hyperphosphorylation of microtubule-associated protein tau in senescence-accelerated mouse (SAM). Mech Ageing Dev. 2005;126(12):1300-1304.

47. Butterfield DA, Poon HF. The senescence-accelerated prone mouse (SAMP8): a model of age-related cognitive decline with relevance to alterations of the gene expression and protein abnormalities in Alzheimer's disease. Exp Gerontol. 2005;40(10):774-783.
48. Flood JF, Harris FJ, Morley JE. Age-related changes in hippocampal drug facilitation of memory processing in SAMP8 mice. Neurobiol Aging. 1996;17(1):15-24.

49. Vorhees CV, Williams MT. Morris water maze: procedures for assessing spatial and related forms of learning and memory. Nat Protoc. 2006;1(2):848-858.

50. Wang T, Wu Z, Sun L, Li W, Liu G, Tang Y. A Computational Systems Pharmacology Approach to Investigate Molecular Mechanisms of Herbal Formula Tian-Ma-Gou-Teng-Yin for Treatment of Alzheimer's Disease. Front Pharmacol. 2018;9:668.

51. Schmidt C, Wolff M, von Ahsen N, Zerr I. Alzheimer's disease: genetic polymorphisms and rate of decline. Dement Geriatr Cogn Disord. 2012;33(2-3):84-89.

52. Murray AP, Faraoni MB, Castro MJ, Alza NP, Cavallaro V. Natural AChE Inhibitors from Plants and their Contribution to Alzheimer's Disease Therapy. Curr Neuropharmacol. 2013;11(4):388-413.

53. Song JH, Yu J, Tan L. Brain-Derived Neurotrophic Factor in Alzheimer's Disease: Risk, Mechanisms, and Therapy. Mol Neurobiol. 2015;52(3):1477-1493.

54. D'Amelio M, Cavallucci V, Middei S, et al. Caspase-3 triggers early synaptic dysfunction in a mouse model of Alzheimer's disease. Nat Neurosci. 2011;14(1):69-76.

55. Jiang P, Li C, Xiang Z, Jiao B. Tanshinone IIA reduces the risk of Alzheimer's disease by inhibiting iNOS, MMP2 and NFkappaBp65 transcription and translation in the temporal lobes of rat models of Alzheimer's disease. Mol Med Rep. 2014;10(2):689-694.

56. Guo LH, Alexopoulos P, Perneczky R. Heart-type fatty acid binding protein and vascular endothelial growth factor: cerebrospinal fluid biomarker candidates for Alzheimer's disease. Eur Arch Psychiatry Clin Neurosci. 2013;263(7):553-560.

57. Lange C, Storkebaum E, de Almodóvar CR, Dewerchin M, Carmeliet P. Vascular endothelial growth factor: a neurovascular target in neurological diseases. Nat Rev Neurol. 2016;12(8):439-454.

58. Hansson O, Palmqvist S, Ljung H, Cronberg T, van Westen D, Smith R. Cerebral hypoperfusion is not associated with an increase in amyloid $\beta$ pathology in middle-aged or elderly people. Alzheimers Dement. 2018;14(1):54-61.

59. Wolters FJ, Zonneveld HI, Hofman A, et al. Cerebral Perfusion and the Risk of Dementia: A Population-Based Study. Circulation. 2017; 136(8):719-728.

60. Ha-Ohoo T, Tomita H, Taki Y, et al. The VEGF gene polymorphism impacts brain volume and arterial blood volume. Hum Brain Mapp. Epub 2017 Apr 12. doi: 10.1002/hbm.23606.

61. Licht T, Rothe G, Kreisel T, et al. VEGF preconditioning leads to stem cell remodeling and attenuates age-related decay of adult hippocampal neurogenesis. Proc Natl Acad Sci U S A. 2016;113(48):E7828-E7836.

62. Di Q, Cheng Z, Kim W, et al. Impaired cross-activation of $\beta 3$ integrin and VEGFR-2 on endothelial progenitor cells with aging decreases angiogenesis in response to hypoxia. Int J Cardiol. 2013;168(3):2167-2176.

63. Lähteenvuo J, Rosenzweig A. Effects of aging on angiogenesis. Circ Res. 2012;110(9):1252-1264.

64. HerranE,Perez-GonzalezR, Igartua M, PedrazJL, Carro E, HernandezRM. Enhanced Hippocampal Neurogenesis in APP/Ps1 Mouse Model of Alzheimer's Disease After Implantation of VEGF-loaded PLGA Nanospheres. Curr Alzheimer Res. 2015;12(10):932-940.

65. Herrán E, Pérez-González R, Igartua M, Pedraz JL, Carro E, Hernández RM. VEGF-releasing biodegradable nanospheres administered by craniotomy: a novel therapeutic approach in the APP/Ps1 mouse model of Alzheimer's disease. J Control Release. 2013;170(1):111-119.

66. Spuch C, Antequera D, Portero A, et al. The effect of encapsulated VEGF-secreting cells on brain amyloid load and behavioral impairment in a mouse model of Alzheimer's disease. Biomaterials. 2010; 31(21):5608-5618.

67. Di Marco LY, Venneri A, Farkas E, Evans PC, Marzo A, Frangi AF. Vascular dysfunction in the pathogenesis of Alzheimer's disease - A review of endothelium-mediated mechanisms and ensuing vicious circles. Neurobiol Dis. 2015;82:593-606. 
68. Kume K, Hanyu H, Sato T, et al. Vascular risk factors are associated with faster decline of Alzheimer disease: a longitudinal SPECT study. J Neurol. 2011;258(7):1295-1303.

69. Gottesman RF, Schneider AL, Zhou Y, et al. Association Between Midlife Vascular Risk Factors and Estimated Brain Amyloid Deposition. JAMA. 2017;317(14):1443-1450.

70. Li J, Wang YJ, Zhang M, et al. Vascular risk factors promote conversion from mild cognitive impairment to Alzheimer disease. Neurology. 2011;76(17):1485-1491.

71. Rodrigue KM, Rieck JR, Kennedy KM, Devous MD, Diaz-Arrastia R, Park DC. Risk factors for $\beta$-amyloid deposition in healthy aging: vascular and genetic effects. JAMA Neurol. 2013;70(5):600-606.

72. Grinán-Ferré C, Corpas R, Puigoriol-Illamola D, Palomera-Ávalos V, Sanfeliu C, Pallàs M. Understanding Epigenetics in the Neurodegeneration of Alzheimer's Disease: SAMP8 Mouse Model. J Alzheimers Dis. 2018;62(3):943-963.

73. Karuppagounder V, Arumugam S, Babu SS, et al. The senescence accelerated mouse prone 8 (SAMP8): A novel murine model for cardiac aging. Ageing Res Rev. 2017;35:291-296.

74. Agabiti-Rosei C, Favero G, de Ciuceis C, et al. Effect of long-term treatment with melatonin on vascular markers of oxidative stress/ inflammation and on the anticontractile activity of perivascular fat in aging mice. Hypertens Res. 2017;40(1):41-50.

75. Bromley-Brits K, Deng Y, Song W. Morris water maze test for learning and memory deficits in Alzheimer's disease model mice. J Vis Exp. 2011;53:2920.

76. Sohanaki H, Baluchnejadmojarad T, Nikbakht F, Roghani M. Pelargonidin Improves Passive Avoidance Task Performance in a Rat Amyloid Beta25-35 Model of Alzheimer's Disease Via Estrogen Receptor Independent Pathways. Acta Med Iran. 2016;54(4):245-250.

77. Ren Z, Zhang R, Li Y, Li Y, Yang Z, Yang H. Ferulic acid exerts neuroprotective effects against cerebral ischemia/reperfusion-induced injury via antioxidant and anti-apoptotic mechanisms in vitro and in vivo. Int J Mol Med. 2017;40(5):1444-1456.

78. Asano T, Matsuzaki H, Iwata N, et al. Protective Effects of Ferulic Acid against Chronic Cerebral Hypoperfusion-Induced Swallowing Dysfunction in Rats. Int J Mol Sci. 2017;18(3):550.

79. Koh PO. Ferulic acid attenuates the down-regulation of MEK/ERK p90RSK signaling pathway in focal cerebral ischemic injury. Neurosci Lett. 2015;588:18-23.

80. Li J, Zeng B, Hu X, et al. Protective Effects of Ginsenoside Rb1 against Blood-Brain Barrier Damage Induced by Human Immunodeficiency Virus-1 Tat Protein and Methamphetamine in Sprague-Dawley Rats. Am J Chin Med. 2018;46(3):551-566.

81. Wang Y, Li Y, Yang W, et al. Ginsenoside Rb1 inhibit apoptosis in rat model of Alzheimer's disease induced by $\mathrm{A} \beta_{1-40}$. Am J Transl Res. 2018; 10(3):796-805.

82. Miao HH, Zhang Y, Ding GN, Hong FX, Dong P, Tian M. Ginsenoside $\mathrm{Rb} 1$ attenuates isoflurane/surgery-induced cognitive dysfunction via inhibiting neuroinflammation and oxidative stress. Biomed Environ Sci. 2017;30(5):363-372.
83. Ahmed T, Raza SH, Maryam A, et al. Ginsenoside Rb1 as a neuroprotective agent: A review. Brain Res Bull. 2016;125:30-43.

84. Jiang Z, Wang Y, Zhang X, et al. Preventive and therapeutic effects of ginsenoside $\mathrm{Rb} 1$ for neural injury during cerebral infarction in rats. Am J Chin Med. 2013;41(2):341-352.

85. Tran TV, Shin EJ, Dang DK, et al. Ginsenoside Re protects against phencyclidine-induced behavioral changes and mitochondrial dysfunction via interactive modulation of glutathione peroxidase-1 and NADPH oxidase in the dorsolateral cortex of mice. Food Chem Toxicol. 2017;110:300-315.

86. Tu TT, Sharma N, Shin EJ, et al. Ginsenoside Re Protects Trimethyltin-Induced Neurotoxicity via Activation of IL-6-Mediated Phosphoinositol 3-Kinase/Akt Signaling in Mice. Neurochem Res. 2017;42(11):3125-3139.

87. Nam Y, Wie MB, Shin EJ, et al. Ginsenoside Re protects methamphetamine-induced mitochondrial burdens and proapoptosis via genetic inhibition of protein kinase $\mathrm{C} \delta$ in human neuroblastoma dopaminergic SH-SY5Y cell lines. J Appl Toxicol. 2015;35(8):927-944.

88. Shen J, Zhao Z, Shang W, et al. Ginsenoside Rg1 nanoparticle penetrating the blood-brain barrier to improve the cerebral function of diabetic rats complicated with cerebral infarction. Int J Nanomedicine. 2017;12:6477-6486

89. Wang Y, Liu Q, Xu Y, et al. Ginsenoside Rg1 Protects against Oxidative Stress-induced Neuronal Apoptosis through Myosin IIA-actin Related Cytoskeletal Reorganization. Int J Biol Sci. 2016;12(11): 1341-1356.

90. Xie CL, Wang WW, Xue XD, Zhang SF, Gan J, Liu ZG. A systematic review and meta-analysis of Ginsenoside-Rg1 (G-Rg1) in experimental ischemic stroke. Sci Rep. 2015;5(1):7790.

91. Kuang X, Zhou HJ, Thorne AH, Chen XN, Li LJ, Du JR. Neuroprotective Effect of Ligustilide through Induction of $\alpha$-Secretase Processing of Both APP and Klotho in a Mouse Model of Alzheimer's Disease. Front Aging Neurosci. 2017;9:353.

92. Kuang X, Chen YS, Wang LF, et al. Klotho upregulation contributes to the neuroprotection of ligustilide in an Alzheimer's disease mouse model. Neurobiol Aging. 2014;35(1):169-178.

93. Wu XM, Qian ZM, Zhu L, et al. Neuroprotective effect of ligustilide against ischaemia-reperfusion injury via up-regulation of erythropoietin and down-regulation of RTP801. Br J Pharmacol. 2011;164(2): 332-343.

94. Zhao T, Fu Y, Sun H, Liu X. Ligustrazine suppresses neuron apoptosis via the Bax/Bcl-2 and caspase-3 pathway in PC12 cells and in rats with vascular dementia. IUBMB Life. 2018;70(1):60-70.

95. Zhang T, Gu J, Wu L, et al. Neuroprotective and axonal outgrowthpromoting effects of tetramethylpyrazine nitrone in chronic cerebral hypoperfusion rats and primary hippocampal neurons exposed to hypoxia. Neuropharmacology. 2017;118:137-147.

96. Li G, Tian Y, Zhang Y, et al. A Novel Ligustrazine Derivative T-VA Prevents Neurotoxicity in Differentiated PC12 Cells and Protects the Brain against Ischemia Injury in MCAO Rats. Int J Mol Sci. 2015; 16(9):21759-21774.
Neuropsychiatric Disease and Treatment

\section{Publish your work in this journal}

Neuropsychiatric Disease and Treatment is an international, peerreviewed journal of clinical therapeutics and pharmacology focusing on concise rapid reporting of clinical or pre-clinical studies on a range of neuropsychiatric and neurological disorders. This journal is indexed on PubMed Central, the 'PsycINFO' database and CAS,

\section{Dovepress}

and is the official journal of The International Neuropsychiatric Association (INA). The manuscript management system is completely online and includes a very quick and fair peer-review system, which is all easy to use. Visit http://www.dovepress.com/testimonials.php to read real quotes from published authors. 